\title{
Study of the Thermal Conductivity of Different Geothermal Grouting Materials with a Homemade Apparatus ${ }^{+}$
}

\author{
Carlos Castán-Fernández 1,* , Germán Marcos-Robredo ${ }^{2}$, Miguel Ángel Rey-Ronco ${ }^{2}$ and \\ Teresa Alonso-Sánchez ${ }^{3}$ \\ 1 Department of Business Administration, University of Oviedo, 33004 Oviedo, Spain \\ 2 Department of Energy, University of Oviedo, 33004 Oviedo, Spain; marcosgerman@uniovi.es (G.M.-R.); \\ rey@uniovi.es (M.Á.R.-R.) \\ 3 Department of Mining Exploitation and Prospecting, University of Oviedo, 33004 Oviedo, Spain; \\ tjalonso@uniovi.es \\ * Correspondence: castancarlos@uniovi.es; Tel.: +34-675-529-212 \\ + Presented at the 2nd International Research Conference on Sustainable Energy, Engineering, Materials and \\ Environment (IRCSEEME), Mieres, Spain, 25-27 July 2018.
}

Published: 5 November 2018

\begin{abstract}
Thermal conductivity is an essential property of the geothermal grout, which in turn is considered the most important element in a vertical closed-loop ground heat exchanger. The main aim of this work is to determine the thermal conductivity of four of the most commonly used geothermal grouting materials using a homemade apparatus, developed by the research team. The tests were also performed with a commercial thermal conductivity meter, the Shotherm QTM-F1. Both the homemade apparatus, called MCT, and the commercial thermal conductivity meter are based on the transient hot wire method. The components used to make the specimens are cement, silica sand, bentonite, water and superplasticizer. A laboratory mortar mixer was used to prepare all mixtures. Later, the samples were cured in a water bath for 7 days and finally the samples were dried at $60^{\circ} \mathrm{C}$ for $24 \mathrm{~h}$ before testing. Each of the samples tested is formed of two solid rectangular prisms of the same material and of the same dimensions $(180 \mathrm{~mm} \times 70 \mathrm{~mm} \times 50 \mathrm{~mm})$. The obtained results with the MCT apparatus are similar to the data reported in the literature and to those obtained using the Shotherm QTM-F1thermal conductivity meter. The deviations of the values measured with the MCT apparatus are, in all cases, less than $10 \%$.
\end{abstract}

Keywords: thermal conductivity; homemade apparatus; geothermal grout

\section{Introduction}

Figure 1 shows the main elements of a vertical closed-loop ground heat exchanger which has a wide variety of applications in buildings (heating, domestic hot water and air conditioning), industrial processes, greenhouses, fish farming or balneotherapy.

In most of the vertical closed-loop ground heat exchangers the material used to fill the gap between the pipe and the borehole wall is the geothermal grout which is considered the most important element in a vertical closed-loop ground heat exchanger.

On the other hand, the thermal conductivity of the geothermal grout plays a vital role in conducting heat to the installation [1]. Geothermal grout should have a high thermal conductivity [2]. This property indicates its ability to transfer heat by conduction. It is given in $\mathrm{W} / \mathrm{m} \cdot \mathrm{K}$ and is typically characterized by the letter $\lambda$. 


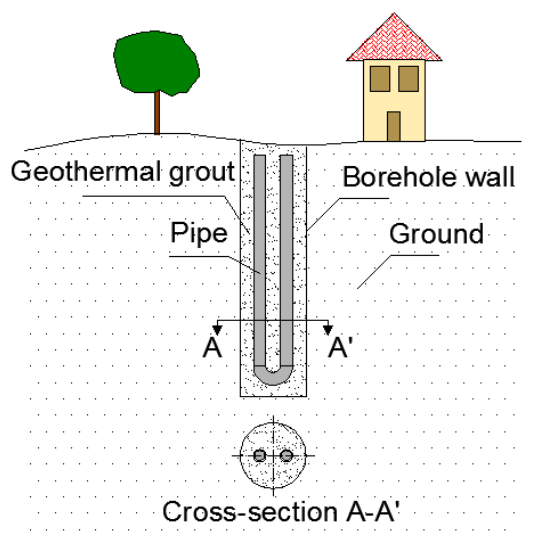

Figure 1. Main elements of a vertical closed-loop ground heat exchanger.

In solid materials thermal energy is transported by the phonons and by the free electrons, being the total thermal conductivity expressed as the sum of the phononic contribution and the electronic contribution [3].

Thermal conductivity varies with the chemical composition, temperature, porosity, water content and particle distribution. The measurement of the thermal conductivity is very difficult and requires high precision in the determination of the parameters involved in its calculation [4].

\section{Materials and Methods}

Four of the most commonly used geothermal grouts have been made. The materials used are: cement (c), silica sand (s), bentonite (b), water (w) and superplasticizer (r). Table 1 shows the materials used for making the four samples. Each of these samples is formed of two solid rectangular prisms of the same material and of the same dimensions $(180 \mathrm{~mm} \times 70 \mathrm{~mm} \times 50 \mathrm{~mm})$. The M1 sample is a bentonite-based grout. The other samples (M2, M3 and M4) are cement-based grouts.

Table 1. Samples and materials used.

\begin{tabular}{cccccc}
\hline Sample & Cement & Silica Sand & Bentonite & Water & Superplasticizer \\
\hline M1 & & & $x$ & $x$ & \\
M2 & $\mathrm{x}$ & & & $x$ & $\mathrm{x}$ \\
M3 & $\mathrm{x}$ & $\mathrm{x}$ & $\mathrm{x}$ & $\mathrm{x}$ & $\mathrm{x}$ \\
M4 & $\mathrm{x}$ & & & & $\mathrm{x}$ \\
\hline
\end{tabular}

Table 2 shows the dosage (by weight) of the four samples where $(\mathrm{s} / \mathrm{c})$ is the silica sand to cement ratio, $(b / c)$ is the bentonite to cement ratio, $(\mathrm{w} / \mathrm{c})$ is the water to cement ratio, $(\mathrm{w} / \mathrm{b})$ is the water to bentonite ratio and $(\mathrm{r} / \mathrm{c})$ is the superplasticizer to cement ratio.

Table 2. Dosage of the samples.

\begin{tabular}{cccccc}
\hline Sample & s/c & $\mathbf{b} / \mathbf{c}$ & w/c & w/b & r/c \\
\hline M1 & & & & 4 & \\
M2 & & & 0.25 & & 0.02 \\
M3 & 2 & & 0.42 & & 0.02 \\
M4 & & 0.20 & 0.52 & & 0.02 \\
\hline
\end{tabular}

Wooden molds have been used (Figure 2a). For making the mixture a laboratory mortar mixer was used (Figure 2b). 


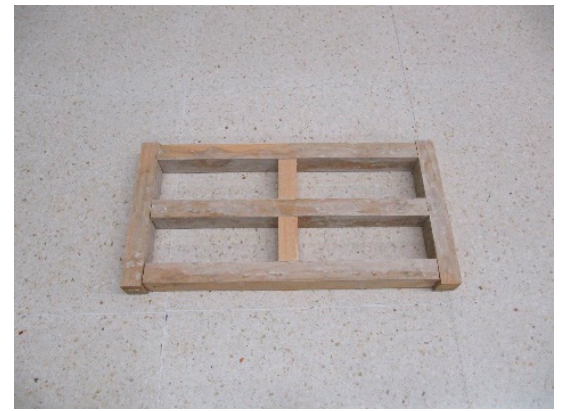

(a)

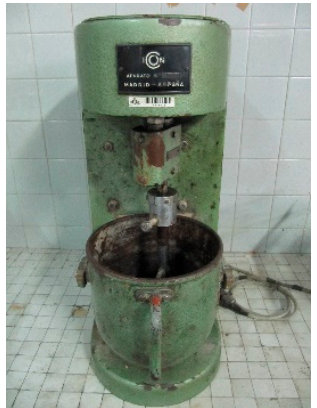

(b)

Figure 2. (a) Mold; (b) Mixer.

The samples were cured in a water bath for 7 days and then they were dried at $60{ }^{\circ} \mathrm{C}$ for $24 \mathrm{~h}$ before testing.

Thermal conductivity was measured using a homemade apparatus developed by the research team and using a commercial thermal conductivity meter (Shotherm QTM-F1). Both the homemade apparatus, called MCT, and the Shotherm QTM-F1 are based on the transient hot wire method. Figure 3 shows the MCT apparatus and Figure 4 shows the Shotherm QTM-F1.

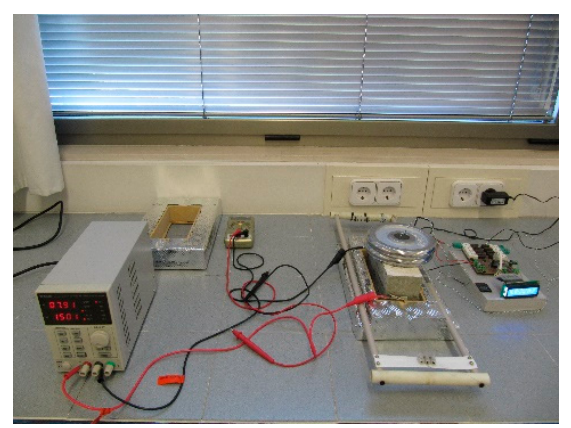

(a)

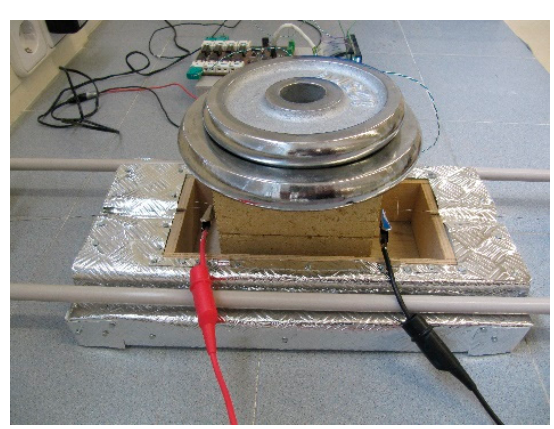

(b)

Figure 3. MCT. (a) General view; (b) Detail view.

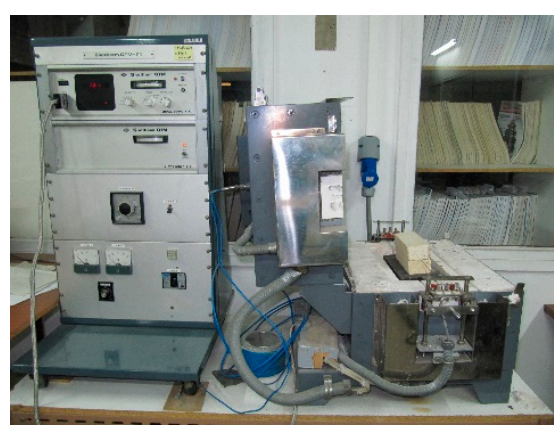

(a)

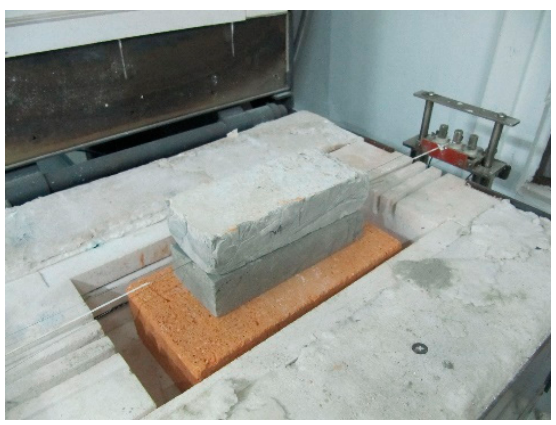

(b)

Figure 4. Shotherm QTM-F1. (a) General view; (b) Detail view.

All the measurements of thermal conductivity were made at room temperature, specifically with a relative humidity of $65 \%$ and a temperature of $25^{\circ} \mathrm{C}$.

Three tests have been performed on each sample. The thermal conductivity of each sample is the average value.

\section{Results and Discussion}

The results of the measurements and the deviations are presented in Table 3. 
Table 3. Thermal conductivity measurements and deviations.

\begin{tabular}{cccccc}
\hline & Literature & Shotherm QTM-F1 & \multicolumn{3}{c}{ MCT } \\
\hline Sample & $\lambda_{\text {Literature }}$ & $\lambda_{\text {Shotherm QTM-F1 }}$ & $\lambda_{\text {MCT }}$ & Deviation to & Deviation to \\
\hline & {$[\mathbf{W} / \mathbf{m} \cdot \mathbf{K}]$} & {$[\mathbf{W} / \mathbf{m} \cdot \mathbf{K}]$} & {$[\mathbf{W} / \mathbf{m} \cdot \mathbf{K}]$} & $\lambda_{\text {Literatura }}$ & $\lambda_{\text {Shotherm QTM-F1 }}$ \\
\hline M1 & 0.70 & 0.71 & 0.70 & +0.00 & -1.41 \\
M2 & 0.80 & 0.79 & 0.82 & +2.50 & +3.80 \\
M3 & 1.50 & 1.63 & 1.58 & +5.33 & -3.07 \\
M4 & 0.80 & 0.84 & 0.81 & +1.25 & -3.57 \\
\hline
\end{tabular}

It can be observed that the obtained results with the MCT apparatus are similar to the data reported in the literature (a maximum deviation of $5.33 \%$ is obtained) and to those obtained using the Shotherm QTM-F1thermal conductivity meter (a maximum deviation of $3.80 \%$ is obtained).

\section{Conclusions}

The thermal conductivity of four of the most commonly used geothermal grouting materials has been measured using a homemade apparatus, developed by the research team, and a commercial thermal conductivity meter.

The deviations of the values measured with the MCT apparatus are, in all cases, less than $10 \%$.

Author Contributions: All authors conceived, designed and performed the experimental campaign. C.C.-F., M.Á.R.-R. and T.A.-S. implemented the methodology and analyzed the results. G.M.-R. provided technical and theoretical support. C.C.-F. wrote the manuscript and all authors read and approved the final version.

Acknowledgments: Authors would like to thank the Government of the Principality of Asturias and the FICYT for providing a Severo Ochoa Grant to the corresponding author of this paper what has made possible the realization of the present work. Authors also want to thank the Department of Materials Science and Metallurgical Engineering of the University of Oviedo, for allowing us to use their facilities during the experimental phase of this research.

Conflicts of Interest: The authors declare no conflict of interest.

\section{References}

1. Sáez Blázquez, C.; Farfán Martín, C.; Martín Nieto, A.; Carrasco García, P.; Sánchez Pérez, D.; GonzálezAguilera, D. Analysis and study of different grouting materials in vertical geothermal closed-loop systems. Renew. Energy 2017, 114, 1189-1200.

2. Indacoechea Vega, I.; Pascual Muñoz, P.; Castro Fresno, D.; Calzada Pérez, M.A. Experimental characterization and performance evaluation of geothermal grouting materials subjected to heatingcooling cycles. Constr. Build. Mater. 2015, 98, 583-592.

3. Montes, J.M.; Cuevas, F.G.; Cintas, J. Ciencia e Ingeniería de los Materiales, 1st ed.; Ediciones Paraninfo S.A.: Madrid, Spain, 2014; pp. 675-676.

4. Dos Santos, W.N.; Gregório, R. Numerical and experimental determination of minimum and maximum measuring times for the hot wire parallel technique. Cerâmica 2003, 49, 29-35.

(c) 2018 by the authors. Licensee MDPI, Basel, Switzerland. This article is an open access article distributed under the terms and conditions of the Creative Commons Attribution (CC BY) license (http://creativecommons.org/licenses/by/4.0/). 